\title{
The influence of systematic pulse-limited physical exercise on the parameters of the cardiovascular system in patients over 65 years of age
}

\author{
Tomasz Chomiuk, Andrzej Folga, Artur Mamcarz
}

$3^{\text {rd }}$ Department of Internal Medicine and Cardiology, Medical University of Warsaw, Poland

Submitted: 23 May 2012

Accepted: 30 November 2012

Arch Med Sci 2013; 9, 2: 201-209

DOI: 10.5114/aoms.2013.34559

Copyright $\odot 2013$ Termedia \& Banach

\author{
Corresponding author: \\ Andrzej Folga MD, PhD \\ $3^{\text {rd }}$ Department \\ of Internal Medicine \\ and Cardiology \\ Medical University of Warsaw \\ 93 Solec St \\ 00-382 Warsaw, Poland \\ Phone: +48 502409409 \\ E-mail: and.folga@gmail.com
}

\begin{abstract}
Introduction: The influence of physical exercise on the parameters of the cardiovascular system of elderly persons has not been sufficiently investigated yet. The aim of the study was to assess the influence of regular 6-week physical exercise using the Nordic walking (NW) method in a group of elderly persons on their physical performance and regulation of selected parameters assessing the cardiovascular system.

Material and methods: Fifty patients over 65 years of age participated in the study. The study encompassed: medical interview, physical examination, resting ECG, spiroergometry examination, 6MWT (6-minute walk test) and 24-hour ambulatory blood pressure monitoring (ABPM). During the exercise programme, the pulse was monitored using pulsometers. After the completion of the training, check-up tests assessing the same parameters were performed. The control group consisted of 18 persons over 65 years of age with similar cardiovascular problems.

Results: In the test group, duration of the physical effort increased by $1.02 \mathrm{~min}$ $(p=0.0001)$, the maximum load increased by $10.68 \mathrm{~W}(p=0.0001)$, values of $\mathrm{VO}_{2 \max }$ by $2.10(p=0.0218)$, distance improved in $6 \mathrm{MWT}$ by $75.04 \mathrm{~m}(p=0.00001)$, systolic blood pressure decreased by $5.50 \mathrm{~mm} \mathrm{Hg}(p=0.035)$ and diastolic blood pressure by $3.50 \mathrm{~mm} \mathrm{Hg}(p=0.054)$ as compared to the control group.

Conclusions: Systematic NW physical exercise limited by the pulse had a beneficial effect on the physical performance of elderly persons as assessed with main parameters. A short 6-week programme of endurance exercises had a hypotensive effect in elderly persons over 65 years of age.
\end{abstract}

Key words: physical exercise, endurance, elderly persons, Nordic walking, blood pressure.

\section{Introduction}

Ageing of society has been a permanent process. Since 1950, the percentage of elderly persons has been constantly on the rise, increasing from $8 \%$ in 1950 to $11 \%$ in 2009 and estimated to reach $22 \%$ in 2050 , according to forecasts [1]. In the second half of the $20^{\text {th }}$ century, the length of human life increased by approximately 20 years. According to the World Health Organization (WHO), the average length of human life will be 73 years in 2025 [2].

In 2004, the WHO presented its strategy in relation to physical activity, diet and health. The publication of the WHO contains information about the 
need to increase physical activity in the population of people all over the world. To decrease the risk of cardiovascular diseases, the report recommends at least 30 min of regular physical exercise with moderate intensity on most days [3]. Physical activity considerably lowers the risk of cardiovascular disease and the significance of this protective factor can be compared with giving up smoking $[4,5]$.

Cardiovascular disease (CVD) is the main cause of death in Europe. Almost a half (48\%) of all deaths are caused by CVD (54\% of deaths among women and $43 \%$ of deaths among men). It is estimated that over 4.3 million people die of CVD every year [6]. Lifestyle modification, especially regular physical exercise, is one of the simplest and most effective forms of preventing and improving the prognosis of the course of cardiovascular disease [7].

\section{Material and methods}

Sixty-eight persons over 65 years of age, studying at the University of the Third Age in Warsaw, participated in the study. Women constituted the majority of the subjects ( $88 \%$ women, $12 \%$ men). After giving informed consent for participation in the study, persons meeting the inclusion criteria were included in the study (Consent of the Bioethics Committee of Warsaw Medical University to conduct research study no. KB/68/2009). The inclusion criteria were the following: age over 65 years, efficient locomotor system enabling exercise, lack of serious disease limiting survival to 6 months, stable course of the heart disease: condition after a myocardial infarction, over 6 months, condition after cardiac and vascular surgery, over 6 months, no hazardous heart rhythm disorders, stable values of arterial pressure. The participants of the project were divided into two groups: the test group consisting of 50 randomly selected persons aged 65 to 84 years (average age 70.7 years) who were subject to a physical exercise programme using the Nordic walking (NW) method, and the control group consisting of 18 randomly selected persons aged 65 to 81 years (average age 69.9 years) who did not take part in the physical exercise programme. The exclusion criteria were the following: age under 65 years, locomotor diseases preventing the introduction of physical exercise, unstable course of cardiovascular disease (recent myocardial infarction, malignant ventricular rhythm disturbances, heart failure in NYHA class III-IV, high/unstable values of arterial pressure), disease limiting survival to 6 months, mental disorders disabling cooperation, condition of up to 6 months after myocardial infarction, vascular interventions after cardiac surgery, lack of informed consent to participate in the study. Each training session would consist of $10 \mathrm{~min}$ warming up, 30 min of proper training with Nordic walking methods and 10 min of cooling down. The proper training was followed by heart rate monitoring with pulsometers. The target heart rate was established during a spiroergometry test prior to the study and was defined as $60-70 \%$ of maximal heart rate. The training sessions took place three times a week.

\section{Research procedures}

The test group consisted of 50 persons over 65 years of age. Before qualification for the exercise programme using aerobic exercise, every person underwent preliminary procedures which involved: medical interview, physical examination, resting ECG, spiroergometry examination, echocardiogram, 6-minute walk test (6MWT) and 24-hour ambulatory blood pressure monitoring (ABPM). The NW exercise schedule was prepared individually for each person after an spiroergometry examination and determination of the maximum exercise pulse (MEP) defined as $60-70 \%$ of the maximum pulse for a given age, including the anaerobic threshold. During the exercise, the pulse of each subject was monitored using a pulsometer. The intensity of exercise was limited by the pulse and individual performance of each subject. After completion of the 6-week training, check-up tests assessing the same parameters were performed. The control group consisted of 18 patients over 65 years of age with similar cardiovascular problems. This group underwent the same tests as the group undertaking physical activity excluding the 6 -week exercise programme using the NW method. The subjects in the 2 groups were receiving similar drug treatment. The characteristics of both groups are shown in Table I.

\section{Statistical analysis}

A generalized estimating equation was used in the analysis of intervention for continuous data with normal distribution. The model includes correlations between observations from the same subject; in this case, these observations were repeated after a period of time. The assumption of normality of distributions of the analysed variables was verified using the Shapiro-Wilk test. Due to deviations from the normality assumptions, the data were logarithmically transformed and/or deviating observations were omitted in the analysis. The data distributions after transformation did not deviate from the normal distribution. The group identifier (test group vs. control group), the time of measurement (follow-up vs. screening) and the interaction between the group and the time of measurement were taken into account in the models. By means of the stepwise elimination method with level 0.1 for staying in the model, variables which were statistically significant at the level of 
0.05 were selected. The effect of group and time and the interaction between the group and time effect were left in the models regardless of their statistical significance.

\section{Results}

No person dropped out of the study in either of the groups. The results obtained during the spiroergometry examinations and ABPM are presented in Tables II and III.

Persons participating in the NW exercise walked longer distances in the 6-minute walk test (on average by $75.04 \mathrm{~m}$, median $=74.00, p=0.00001$ ) than persons from the control group (on average by 2.39 , median $=0.50$ ), Figure 1 . Owing to the application of the exercise programme, in the test group, the duration of physical effort increased (on average by 1.02 min, median $=0.85, p=0.0001$ ), during the spiroergometry examination, compared with the control group, in which this time was slightly shortened (on average by $0.62 \mathrm{~min}$, median $=-0.42$ ). The test group also achieved higher effort load values (on average by $10.68 \mathrm{~W}$, median $=-8.00$, $p=0.0001$ ) than the control group (on average, a decrease by $6.11 \mathrm{~W}$, median $=-4.00$ ) (Figure 2) and the $\mathrm{VO}_{2 \max }$ values changed significantly - the value of this parameter increased in the test group (on average by 2.10 , median $=1.85, p=0.0218$ ) and decreased in the control group (mean value $=-0.37$, median $=0.70$ ) (Figure 2).

No differences occurred between the test group and the control group with respect to the remaining analysed parameters, such as the time to the anaerobic threshold, load at the anaerobic point, $\mathrm{O}_{2}$-pulse, maximum effort heart rate, maximum minute ventilation, and maximum arterial pressure during effort.

The analysis of results of the blood pressure parameters and the heart rate in an ABPM showed that the systolic blood pressure was lowered on average by $4.94 \mathrm{~mm} \mathrm{Hg}$ (median $=-5.50, p=0.0352$ ) in the test group, and it rose on average by 0.22 (median $=2.00$ ) in the control group. The remaining parameters under analysis - change of the diastolic pressure and the average daily pulse - did not change significantly, although a tendency for lower values after the application of the NW exercise was observed in the active group $(p=0.054)$. The results of the blood pressure measurements are presented in Table III. The change in the tested parameters is shown in Figure 3.

\section{Discussion}

Physical performance decreasing with age is a physiological phenomenon. There are more and more studies confirming the beneficial effect of physical exercise on the physical and mental
Table I. Clinical characteristics of persons included in the study

\begin{tabular}{|c|c|c|}
\hline Features & $\begin{array}{c}\text { Test group } \\
n(\%)\end{array}$ & $\begin{array}{c}\text { Control group } \\
n(\%)\end{array}$ \\
\hline \multicolumn{3}{|l|}{ Gender } \\
\hline Women & $44(88)$ & $16(88.24)$ \\
\hline Men & $6(12)$ & $2(11.76)$ \\
\hline Age (average) [years] & 70.68 & 69.89 \\
\hline $\begin{array}{l}\text { Body mass index } \\
\text { (average) }\left[\mathrm{kg} / \mathrm{m}^{2}\right]\end{array}$ & 26.38 & 27.46 \\
\hline $\begin{array}{l}\text { Body surface area } \\
\text { (average) }\left[\mathrm{m}^{2}\right]\end{array}$ & 1.75 & 1.74 \\
\hline Ischaemic heart disease & $11(22)$ & $3(16.67)$ \\
\hline Hypertension & $30(60)$ & $11(61.11)$ \\
\hline Dyslipidaemia & $28(56)$ & $9(50)$ \\
\hline Smoking & $3(6)$ & $2(11.11)$ \\
\hline Diabetes & $4(8)$ & $3(16.67)$ \\
\hline $\begin{array}{l}\text { Chronic obstructive } \\
\text { pulmonary disease }\end{array}$ & $1(2)$ & $1(5.56)$ \\
\hline Asthma bronchiale & $2(4)$ & $1(5.56)$ \\
\hline Stroke & 0 & 0 \\
\hline $\begin{array}{l}\text { History of myocardial } \\
\text { infarction }\end{array}$ & 0 & 0 \\
\hline Osteoporosis & $1(2)$ & $1(5.56)$ \\
\hline Hypothyroidism & $12(24)$ & $4(22.22)$ \\
\hline Atrial fibrillation & $3(6)$ & $2(11.11)$ \\
\hline Heart failure & 0 & $2(11.11)$ \\
\hline
\end{tabular}

spheres of elderly persons in the available literature [8-11].

The duration of effort and load increase after the application of a systematic physical exercise programme, as it is the body's adaptive response to physical effort, which is confirmed by the authors' own study and by the results obtained by other researchers $[8,9,12]$. The results of the present authors' research have shown an increase in the duration of effort in the spiroergometry examination after the completion of the exercise programme. Other researchers also noted the extension of the treadmill stress test (by 33\%) among elderly persons (aged 80-92 years) after a 6-month exercise programme. Elderly persons taking part in the study were subjected to moderate-intensity endurance exercise 2 or 3 times a week. The training consisted of 20-30 min of proper effort preceded by a warm-up and finished by cool-down exercises [13].

The $\mathrm{O}_{2}$-pulse is considered to be a good parameter assessing the efficiency of the cardiovascular system during physical effort [14, 15]. In this study, no significant improvement in the $\mathrm{O}_{2}$-pulse was observed after the 6-week exercise programme. 
Table II. Parameters of preliminary screening and final tests assessing physical performance obtained in the ergospirometry test and the 6-minute walk test

\begin{tabular}{|c|c|c|c|c|c|}
\hline \multirow[t]{2}{*}{ Features } & & \multicolumn{2}{|c|}{ Preliminary screening parameters } & \multicolumn{2}{|c|}{ Final test parameters } \\
\hline & & Test group & Control group & Test group & Control group \\
\hline \multirow[t]{5}{*}{ Time to anaerobic threshold [min] } & Min & 2.33 & 3.50 & 2.17 & 2.67 \\
\hline & Max & 9.50 & 7.17 & 9.67 & 7.00 \\
\hline & Mean & 5.15 & 5.37 & 4.97 & 5.11 \\
\hline & SD & 1.74 & 1.09 & 1.53 & 1.27 \\
\hline & Median & 5.17 & 5.58 & 4.83 & 5.25 \\
\hline \multirow[t]{5}{*}{ Load at the anaerobic point [W] } & Min & 26.00 & 43.00 & 28.00 & 33.00 \\
\hline & Max & 110.00 & 82.00 & 104.00 & 79.00 \\
\hline & Mean & 60.45 & 62.11 & 57.86 & 57.50 \\
\hline & SD & 17.25 & 10.99 & 15.16 & 11.81 \\
\hline & Median & 60.00 & 63.50 & 56.50 & 59.00 \\
\hline \multirow[t]{5}{*}{ Duration of effort [min] } & Min & 2.50 & 4.28 & 3.72 & 2.67 \\
\hline & Max & 10.95 & 14.33 & 11.95 & 13.87 \\
\hline & Mean & 7.09 & 7.10 & 8.11 & 6.47 \\
\hline & SD & 1.93 & 2.22 & 1.81 & 2.37 \\
\hline & Median & 7.11 & 6.61 & 8.15 & 6.48 \\
\hline \multirow[t]{5}{*}{ Maximum effort load [W] } & Min & 26.00 & 53.00 & 47.00 & 33.00 \\
\hline & Max & 119.00 & 153.00 & 129.00 & 149.00 \\
\hline & Mean & 80.14 & 80.67 & 90.82 & 74.56 \\
\hline & SD & 19.77 & 22.31 & 18.27 & 24.07 \\
\hline & Median & 80.00 & 76.00 & 93.50 & 74.50 \\
\hline \multirow[t]{5}{*}{$\mathrm{O}_{2}$-pulse } & Min & 4.20 & 4.60 & 3.40 & 3.30 \\
\hline & Max & 13.00 & 15.30 & 27.50 & 13.60 \\
\hline & Mean & 8.75 & 8.50 & 9.97 & 8.85 \\
\hline & SD & 2.31 & 3.13 & 3.68 & 2.82 \\
\hline & Median & 8.35 & 7.90 & 9.35 & 9.35 \\
\hline \multirow[t]{5}{*}{$\mathrm{VO}_{2 \max }[\mathrm{ml} / \mathrm{kg} / \mathrm{min}]$} & Min & 6.80 & 10.90 & 6.20 & 4.20 \\
\hline & Max & 24.30 & 24.40 & 26.20 & 25.70 \\
\hline & Mean & 15.38 & 14.83 & 17.48 & 14.56 \\
\hline & SD & 3.85 & 3.53 & 3.61 & 5.15 \\
\hline & Median & 15.70 & 13.90 & 17.20 & 14.65 \\
\hline \multirow[t]{5}{*}{ 6MWT [m] } & Min & 422.00 & 452.00 & 452.00 & 411.00 \\
\hline & Max & 708.00 & 795.00 & 782.00 & 783.00 \\
\hline & Mean & 537.90 & 519.83 & 612.94 & 522.22 \\
\hline & SD & 68.00 & 77.07 & 80.88 & 81.62 \\
\hline & Median & 525.50 & 492.00 & 603.50 & 511.50 \\
\hline
\end{tabular}

6MWT-6-minute walk test

Other authors observed an increase in the $\mathrm{O}_{2}$-pulse parameter (by 8.6\%) after a 6-month exercise programme in a study conducted in the United States and involving elderly persons aged over 80 years (80-92 years of age). No improvement in the $\mathrm{O}_{2}$-pulse parameter was observed during the first
4 stages of this study; only a 6-month training programme led to a significant improvement in this parameter [13]. Thus, it can be concluded that short-term physical training in elderly persons does not lead to an increase in the $\mathrm{O}_{2}$-pulse. Previously conducted research, which showed an increase in 
Table III. Parameters of the preliminary screening and final tests assessing blood pressure and heart rate in 24-hour ambulatory blood pressure monitoring

\begin{tabular}{|c|c|c|c|c|c|}
\hline \multirow[t]{2}{*}{ Features } & & \multicolumn{2}{|c|}{ Preliminary screening parameters } & \multicolumn{2}{|c|}{ Final test parameters } \\
\hline & & Test group & Control group & Test group & Control group \\
\hline \multirow[t]{5}{*}{ SBP $[\mathrm{mm} \mathrm{Hg}]$} & Min & 110.00 & 101.00 & 108.00 & 103.00 \\
\hline & Max & 153.00 & 148.00 & 148.00 & 153.00 \\
\hline & Mean & 134.61 & 122.04 & 129.67 & 122.26 \\
\hline & SD & 13.11 & 12.76 & 11.79 & 13.79 \\
\hline & Median & 136.00 & 121.00 & 133.00 & 119.00 \\
\hline \multirow[t]{5}{*}{$\mathrm{DBP}[\mathrm{mm} \mathrm{Hg}]$} & Min & 57.00 & 48.00 & 62.00 & 54.00 \\
\hline & Max & 88.00 & 93.00 & 95.00 & 90.00 \\
\hline & Mean & 75.67 & 70.68 & 73.22 & 71.38 \\
\hline & SD & 8.46 & 8.35 & 8.04 & 8.47 \\
\hline & Median & 75.50 & 71.00 & 72.50 & 71.00 \\
\hline \multirow[t]{5}{*}{$\mathrm{HR} / 24 \mathrm{~h}$ [beats/min] } & Min & 57.00 & 57.00 & 49.00 & 60.00 \\
\hline & Max & 84.00 & 88.00 & 83.00 & 89.00 \\
\hline & Mean & 70.24 & 74.56 & 69.14 & 71.56 \\
\hline & SD & 6.02 & 8.95 & 6.68 & 7.94 \\
\hline & Median & 71.00 & 77.00 & 70.00 & 71.00 \\
\hline
\end{tabular}

$S B P$ - systolic blood pressure, DBP - diastolic blood pressure, $H R / 24 \mathrm{~h}$ - average heart rate in the 24-hour examination

this index, used exercise programmes lasting 12 weeks and 6 months. There are too few studies including the $\mathrm{O}_{2}$-pulse index to make it possible to provide an unambiguous answer of what "dose" of exercise may have a significant effect on its improvement.

The influence of ageing on the ability to undertake physical effort varies greatly and depends on the individual condition and regular physical activity [16]. The maximal oxygen uptake $\left(\mathrm{VO}_{2 \max }\right)$ is the highest between the $20^{\text {th }}$ and $30^{\text {th }}$ year of life and then it begins to fall at a rate of approximately $1 \%$ per year and depends on the individual level of physical activity (it decreases at a faster rate in persons with a sedentary lifestyle than in physically active persons) $[17,18]$. It was proven that controlled physical effort of appropriate intensity ( $\geq 60 \%$ of the training $\mathrm{VO}_{2 \text { max }}$ ), frequency ( $\geq 3$ days during a week) and length ( $\geq 16$ weeks) may significantly increase $\mathrm{VO}_{2 \max }$ in healthy middle-aged and elderly persons. An extensive meta-analysis performed by researchers showed that the average increase in the $\mathrm{VO}_{2 \max }$ after 16 to 20 weeks of exercise amounted to $3.8 \mathrm{ml} / \mathrm{kg} / \mathrm{min}$ or $16.3 \%$, compared with the control group of persons who did not exercise in the period in question. Better results in the improvement of $\mathrm{VO}_{2 \max }$ were observed after a longer exercise period (from 20 to 30 weeks), but higher-intensity effort does not necessarily bring positive effects (at the level of $>70 \% \mathrm{VO}_{2 \max }$ ) [19].

This study shows that systematic physical exercise lasting for a shorter period of time ( 6 weeks)

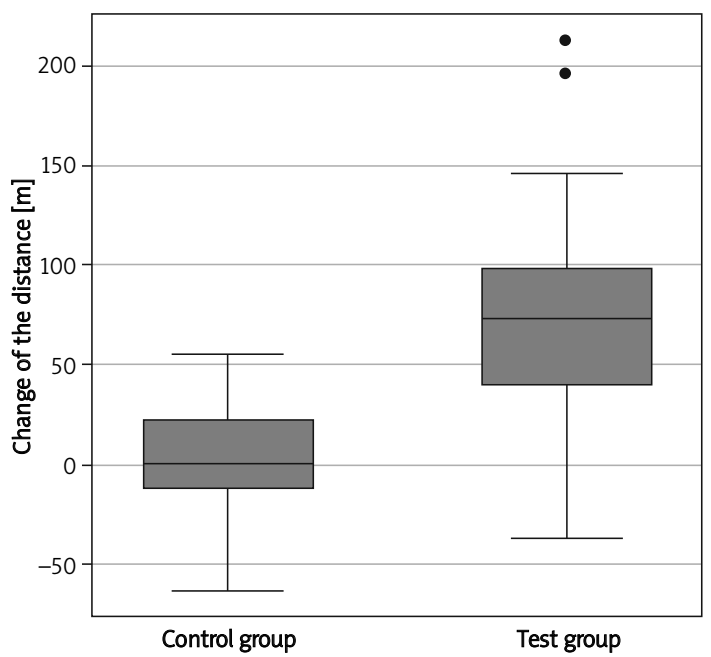

Figure 1. Change of the duration of effort and distance in the 6-minute walk test

can significantly improve the $\mathrm{VO}_{2 \max }$ index (an increase by $2.1 \mathrm{ml} / \mathrm{kg} / \mathrm{min})$. Similar results were obtained in a study involving elderly men (average age: 68 years) in which exercise significantly improved the $\mathrm{VO}_{2 \max }$ after 6 weeks (an increase by $2.4 \mathrm{ml} / \mathrm{kg} / \mathrm{min})$. Medium-intensity training sessions $\left(70 \% \mathrm{VO}_{2 \max }\right)$ using a cycloergometer were held three times a week and each session lasted $45 \mathrm{~min}$. The test group consisted of only 8 participants [20]. Another meta-analysis focusing on elderly persons showed that the length of a single training session is another significant factor affecting the improve- 

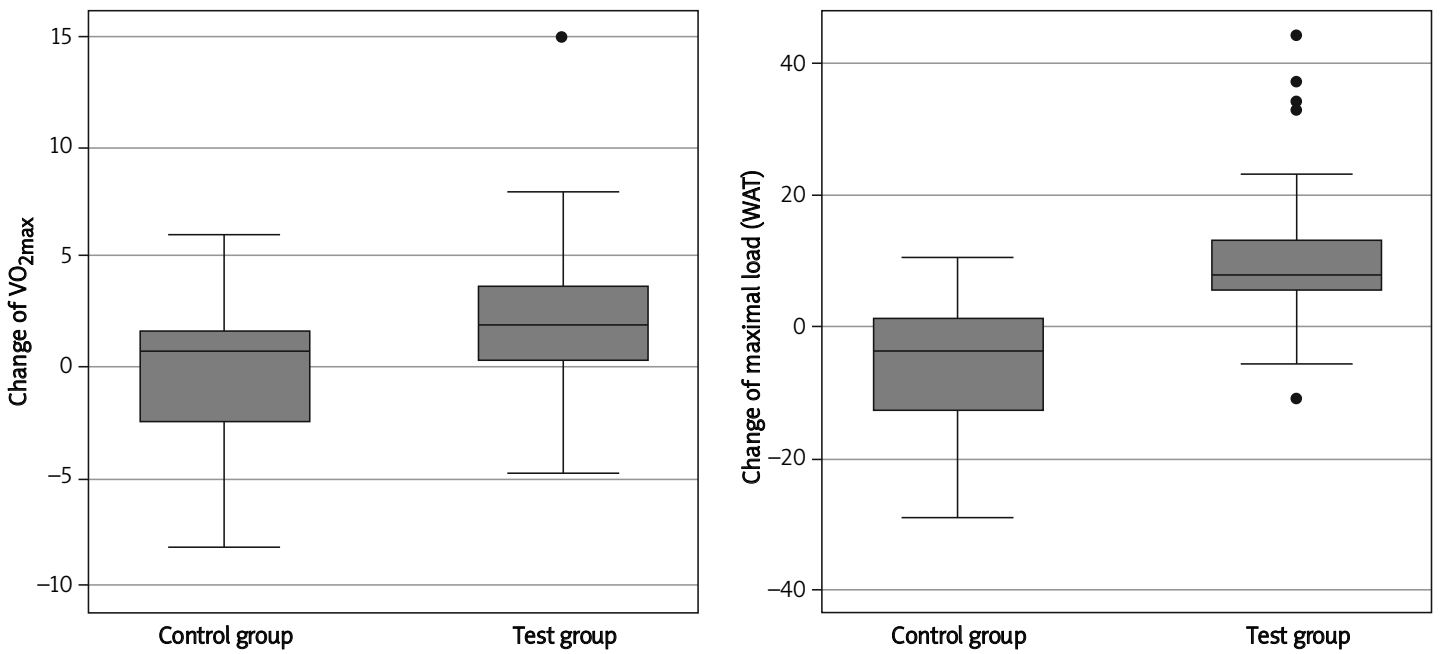

Figure 2. Change of $\mathrm{VO}_{2 \max }$ and change of maximum effort load in the spiroergometry test
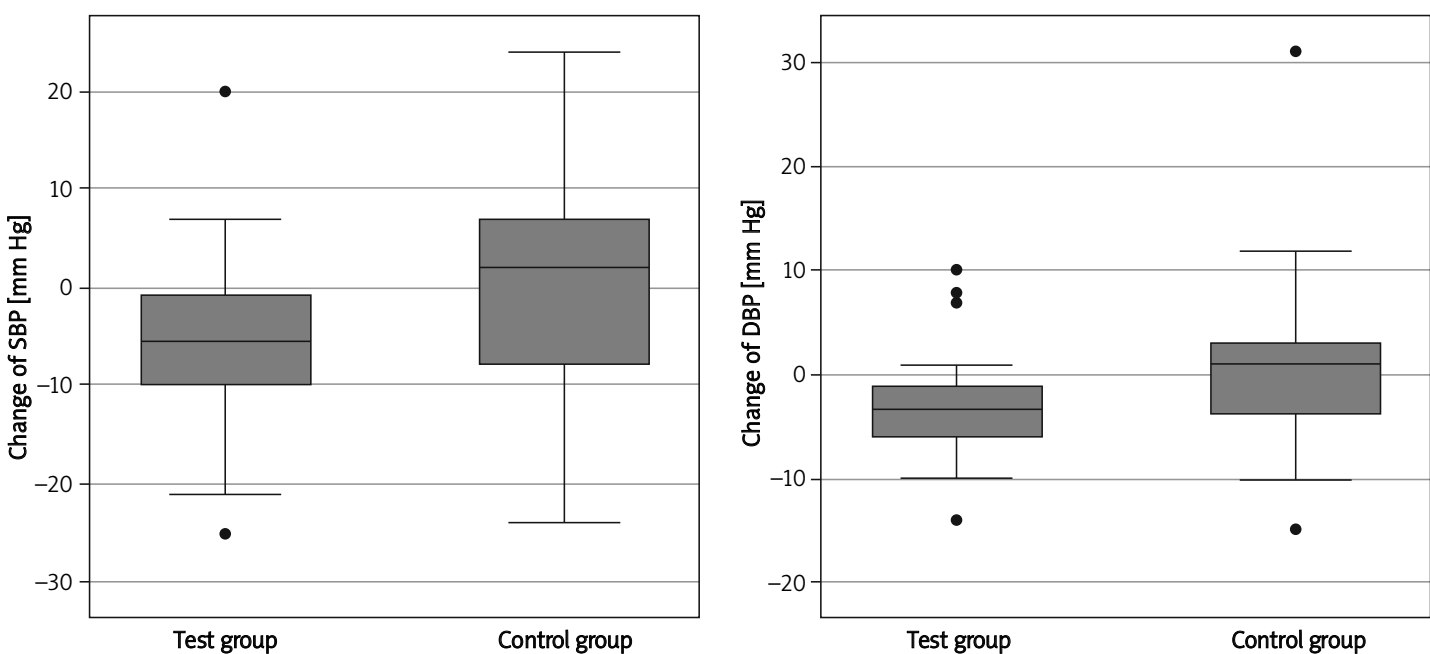

Figure 3. Change of the systolic (SBP) and diastolic blood pressure (DBP) in 24-hour ambulatory blood pressure monitoring

ment in physical performance. Exercise lasting over 30 min resulted in a higher increase in the $\mathrm{VO}_{2 \max }$ $(1.59 \mathrm{ml} / \mathrm{kg} / \mathrm{min})$ [21]. This study revealed that medium-intensity physical exercise has a significant influence on the increase of the $\mathrm{VO}_{2 \max }$ (by $2.1 \mathrm{ml} /$ $\mathrm{kg} / \mathrm{min})$. A decrease in the $\mathrm{VO}_{2 \max }$ is an independent risk factor for all causes of death due to cardiovascular disease and may contribute to premature death in a population of middle-aged and elderly persons [22]. Therefore, increasing the $\mathrm{VO}_{2 \max }$ value by the application of physical training may be of significant clinical importance for persons over 65 years of age.

6MWT is currently commonly used for assessing the functional capacity of patients suffering from pulmonary and cardiovascular diseases [23]. It is also used as a prognostic factor of the incidence and fatality rates in patients with left ventricular dysfunction [24, 25], advanced heart failure [26] and chronic obstructive pulmonary disease [27].
Owen and Croucher examined the influence of a 12-week physical exercise programme in elderly patients (average age of 81 years) with heart failure. The group of persons who exercised were able to walk a longer distance (40.1 m more) than the control group in the 6MWT [28]. Studies performed on healthy elderly subjects (age of the test group $77.2 \pm 3.6$ ) confirm the body's adaptive response to physical effort, which is proved by increasing the walking distance (by 10\%) in the 6MWT after oneyear long physical training [29]. Another study in which the influence of systematic training on the distance covered in the 6MWT involved the participation of 98 elderly women (58 in the test group and 40 in the control group) ( $>60$ years old) suffering from hypertension. The exercise programme conducted by Cunha et al. was similar to that used in the present study, as it consisted of the application of exercise (mostly walking) 3 times a week at an intensity ranging from $55 \%$ to $75 \%$ of the theo- 
retical maximal pulse. The main difference lay in the length of the programme used and the type of walk. In the aforementioned study, the training sessions lasted 16 weeks, while in the present study training lasted 6 weeks. Both programmes resulted in the improvement of the distance covered in the 6MWT. In the study by Cunha et al., between the preliminary test and the final test the distance increased by $70.58 \mathrm{~m}(p<0001)$ [30]. In the present study, despite a shorter exercise programme, it was possible to extend the distance in the 6MWT on average by $75.04 \mathrm{~m}(p<0.00001)$. The comparable positive effect probably results from the type of walk used and NW may be a more effective type of effort than ordinary walking, which still needs to be confirmed by other studies.

The ageing process is connected with a higher frequency of hypertension, ischaemic heart disease, heart failure and reduced effort tolerance [31]. In this study, hypertension was present in $60 \%$ of the subjects from the test group and $61.11 \%$ of the persons from the control group.

Treatment of hypertension is one of the most important goals of the prevention of cardiovascular events [32]. It has been proven by numerous studies that regular physical activity is a non-pharmacological method of achieving a hypotensive effect, regardless of the subjects' age. Systematic endurance exercises lasting 6 weeks contributed to the lowering of ambulatory systolic blood pressure (ASBP) by $5.50 \mathrm{~mm} \mathrm{Hg}$ ( $p=0.035$ ) (24-hour measurement) and lowering of the ambulatory diastolic blood pressure (ADBP) by $3.50 \mathrm{~mm} \mathrm{Hg}(p=0.054)$ (24-hour measurement), compared with the control group. Studies by numerous authors have attempted to explain the influence of physical exercise on lowering of blood pressure (BP) in persons at various ages as well as in persons suffering from cardiovascular disease. So far, the hypotensive effect of physical training in persons suffering from hypertension has been fully documented by researchers the most.

The influence of endurance exercises on ABPM in persons with normal BP has not been examined in a detailed manner. The ABPM is found to predict future cardiovascular risk better than conventional blood pressure [33]. It has been shown in numerous studies [34-38] that BP decreased after the application of endurance exercises, but in some cases, no such relation was observed [39]. A metaanalysis of the randomized controlled studies on endurance training has shown that a decrease in $\mathrm{BP}$ is most noticeable in groups of persons suffering from hypertension (-6.9 mm Hg/-4.9 mm Hg), but a statistically significant decrease in BP was also observed in persons with normal BP values $(-2.4 \mathrm{~mm} \mathrm{Hg} /-1.6 \mathrm{~mm} \mathrm{Hg})$ and those with prehypertension $(-1.7 \mathrm{~mm} \mathrm{Hg} /-1.7 \mathrm{~mm} \mathrm{Hg})$. The results obtained applied to endurance training lasting $40 \mathrm{~min}$ on average, 3 times a week with an intensity of $65 \% \mathrm{HRmax}$ for 16 weeks [40]. One of the studies assessing the influence of 16-week endurance training focused on elderly persons (average age 68.5 years) with normal BP. The intensity of exercise ranged from $50 \%$ to $85 \%$ of the maximum $\mathrm{HR}$. The results of the analysis confirm the hypotensive effect of physical exercise [35].

Numerous studies confirm the lowering of the systolic blood pressure (SBP) owing to the application of a walking exercise programme [41-44]. Diastolic blood pressure (DBP) was successfully lowered in elderly persons in research by Cononie et al. and in middle-aged women in a study by Palmer [45, 46]. Other studies revealed reduced SBP and DBP after the application of an endurance walking programme [47-49]. The analysis of studies concerning the influence of a walking exercise programme on the BP value showed that differences of BP between the test group and the control group, after the completion of the training programme, ranged from $-5.2 \mathrm{~mm} \mathrm{Hg}$ to $-11.0 \mathrm{~mm} \mathrm{Hg}$ for SBP and from $-3.8 \mathrm{~mm} \mathrm{Hg}$ to $-7.7 \mathrm{~mm} \mathrm{Hg}$ for DBP [50].

Numerous studies confirm a reduction in BP after the introduction of systematic endurance exercises in elderly people. However, exercises must be performed on a regular basis as abandoning this routine is connected with loss of the hypotensive effect [13]. The population of senior citizens suffering from hypertension should engage in physical activity combined with appropriate diet as an element of non-pharmacological activity, because, as shown by the TONE study (Trial Of Non-Pharmacological Intervention in the Elderly), it is more effective in elderly persons than in young ones [51]. Regular physical exercise may prevent an increase in hypertension connected with the normal ageing process of the body.

The exercise used in the present study did not have a significant influence on the elderly persons' $H R$. As revealed by other studies, physical exercise must be used for an extended period of time to achieve a reduction in this parameter. It was found that the resting $H R$ reduction among elderly persons was greater and more significant in a group of subjects who had exercised for more than 30 weeks [19].

The number of participants of the study is relatively small. Additionally, $18 \%$ of the patients received $\beta$-adrenolytic agents, which could have influenced the results.

In conclusion, physical training is an effective method to improve the function of the cardiovascular system in elderly persons, who experience unfavourable changes within this system as a result of the ageing process. Systematic physical exercise (Nordic walking) limited by the pulse has a benefi- 
cial effect on the main parameters assessing the physical performance of elderly persons. Even a short 6-week programme of endurance exercises has a hypotensive effect in elderly persons over 65 years of age.

\section{Acknowledgments}

This research was supported by the Medical University of Warsaw, Poland and thanks to a European Union grant for young doctors, "Mazovia PhD Grant", financed by the European Union Social Fund together with the state budget in accordance with the Integrated Operational Programme of Regional Development. The authors would like to thank Interplastic ${ }^{\circledR}$ and Medic-Mar ${ }^{\circledR}$ for granting the equipment.

\section{References}

1. The 2009 Ageing Report, Economic and budgetary projections for the EU-27 Member States (2008-2060), European Economy, 2009 http://ec.europa.eu/economy finance/publications/publication14992_en.pdf, 21.02.2011.

2. Alencar NA, Ferreira MA, Bezerra JC, Vale RGS, Dantas EHM. Levels of physical activity and quality of life in elderly women practitioners of formal and non-formal physical activities. Acta Medica Lituanica 2009; 16: 155-8.

3. World Health Organization (WHO), Global strategy on diet and physical activity. WHO: Geneva, 2004, www.who. int/gb/ebwha/pdf_files/WHA57/A57_9-en.pdf. Accessed 06.03.2011.

4. Mora S, Lee IM, Buring JE, Ridker PM. Association of physical activity and body mass index with novel and traditional cardiovascular biomarkers in women. JAMA 2006; 295: 1412-9.

5. Manson JE, Greenland P, LaCroix AZ, et al. Walking compared with vigorous exercise for the prevention of cardiovascular events in women. N Engl J Med 2002; 347: 716-25.

6. Allender S, Scarborough P, Peto V, et al. European cardiovascular disease statistics 2008. European Heart Network. Brussels 2008.

7. Kappagoda CT, Amsterdam EA. Improving guidelines for the management of coronary heart disease risk factors. Arch Med Sci 2011; 7: 923-4.

8. Kallinen M, Sipilä S, Alen M, Suominen H. Improving cardiovascular fitness by strength or endurance training in women aged 76-78 years. A population-based, randomized controlled trial. Age Ageing 2002; 31: 247-54.

9. Pogliaghi S, Terziotti P, Cevese A, Balestreri F, Schena F. Adaptations to endurance training in the healthy elderly: arm cranking versus leg cycling. Eur J Appl Physiol 2006; 97: 723-31.

10. Huang G, Gibson CA, Tran ZV, Osness WH. Controlled endurance exercise training and $\mathrm{VO} 2 \mathrm{max}$ changes in older adults: a meta-analysis. Prev Cardiol 2005; 8: 217-25.

11. Devereux K, Robertson D, Briffa NK. Effects of a waterbased program on women 65 years and over. A randomised controlled trial. Austral J Physiother 2005; 51: 102-8.

12. Delagardelle C, Feiereisen P, Autier P, Shita R, Krecke R, Beissel J. Strength/endurance training versus endurance training in congestive heart failure. Med Sci Sports Exerc 2002; 34: 1868-72.

13. Vaitkevicius PV, Ebersold C, Shah MS, et al. Effects of aerobic exercise training in community-based subjects aged 80 and older: a pilot study. J Am Geriatr Soc 2002; 50: 2009-13.

14. Patterson RP, Remole WD. The response of the oxygen pulse during a stress test in patients with coronary artery disease. Cardiology 1981; 67: 52-62.

15. Holverda S, Bogaard HJ, Groepenhoff H, Postmus PE, Boonstra A, Vonk-Noordegraaf A. Cardiopulmonary exercise test characteristics in patients with chronic obstructive pulmonary disease and associated pulmonary hypertension. Respiration 2008; 76: 160-7.

16. Amra B, Kelishadi R, Golshan M. Peak oxygen uptake of healthy Iranian adolescents. Arch Medi Sci 2009; 5: 69-73.

17. Chodzko-Zajko WJ, Proctor DN, Fiatarone Singh MA, et al. American College of Sports Medicine position stand, Exercise and physical activity for older adults. Med Sci Sports Exerc 2009; 41: 1510-30.

18. Sharma G, Goodwin J. Effect of aging on respiratory system physiology and immunology. Clin Interv Aging 2006; 1: 253-60.

19. Huang G, Shi X, Davis-Brezette JA, Osness WH. Resting heart rate changes after endurance training in older adults: a meta-analysis. Med Sci Sports Exerc 2005; 37: 1381-6.

20. Murias JM, Kowalchuk JM, Paterson DH. Time course and mechanisms of adaptations in cardiorespiratory fitness with endurance training in older and young men. J Appl Physiol 2010; 108: 621-7.

21. Lemura LM, von Duvillard SP, Mookerjee S. The effects of physical training of functional capacity in adults. Ages 46 to 90: a meta-analysis. J Sports Med Phys Fitness 2000; 40: 1-10.

22. Posner JD, McCully KK, Landsberg LA, et al. Physical determinants of independence in mature women. Arch Phys Med Rehabil 1995; 76: 373-80.

23. Swisher A, Goldfarb A. Use of the six-minute walk/run test to predict peak oxygen consumption in older adults. Cardiopulm Phys Ther 1998; 9: 3-5.

24. Milligan NP, Havey J, Dossa A. Using a 6-minute walk test to predict outcomes in patients with left ventricular dysfunction. Rehabil Nurs 1997; 22: 177-81.

25. Bittner V, Weiner DH, Yusuf S, et al. Prediction of mortality and morbidity with a 6-minute walk test in patients with left ventricular dysfunction. JAMA 1993; 270: 1702-7.

26. Cahalin LP, Mathier MA, Semigran MJ, Dec GW, DiSalvo TG. The six-minute walk test predicts peak oxygen uptake and survival in patients with advanced heart failure. Chest 1996; 110: 325-32.

27. Kadikar A, Maurer J, Kesten S. The six-minute walk test: a guide to assessment for lung transplantation. J Heart Lung Transplant 1997; 16: 313-9.

28. Owen A, Croucher L. Effect of an exercise programme for elderly patients with heart failure. Eur J Heart Fail 2000; 2: 65-70.

29. Deley G, Kervio G, Van Hoecke J, Verges B, Grassi B, Casillas JM. Effects of a one-year exercise training program in adults over 70 years old: a study with a control group. Aging Clin Exp Res 2007; 19: 310-5.

30. Cunha CRL, Ferreira MA, Bezerra JCP, Guerral I, Dantas EHM. Aerobic capacity of elderly women engagedin controlled physical activity. J Hum Kinet 2010; 23: 63-9.

31. Wei JY. Age and the cardiovascular system. N Engl J Med 1992; 327: 1735-9.

32. Barylski M, Małyszko J, Rysz J, Myśliwiec M, Banach M. Lipids, blood pressure, kidney - what was new in 2011? Arch Med Sci 2011; 7: 1055-66. 
33. Sethi A, Arora R. Ambulatory blood pressure as a predictor of cardiovascular risk. Arch Med Sci 2009; 5: 3-9.

34. Fagard RH. Exercise is good for your blood pressure: effects of endurance training and resistance training. Clin Exp Pharmacol Physiol 2006; 33: 853-6.

35. Jessup JV, Lowenthal DT, Pollock ML, Turner T. The effects of endurance exercise training on ambulatory blood pressure in normotensive older adults. Geriatr Nephrol Urol 1998; 8: 103-9.

36. Ohkubo T, Hozawa A, Nagatomi R, et al. Effects of exercise training on home blood pressure values in older adults: a randomized controlled trial. J Hypertens 2001; 19; 1045-52.

37. Fortmann SP, Haskell WL, Wood PD. Effects of weight loss on clinic and ambulatory blood pressure in normotensive men. Am J Cardiol 1988; 62: 89-93.

38. Zemva A, Rogel P. Gender differences in athlete's heart: association with 24-h blood pressure. A study of pairs in sport dancing. Int J Cardiol 2001; 77: 49-54.

39. Cox KL, Puddey IB, Morton AR, Burke V, Beilin LJ, McAleer $M$. Exercise and weight control in sedentary overweight men: effects on clinic and ambulatory blood pressure. J Hypertens 1996; 14: 779-90.

40. Cornelissen VA, Fagard RH. Effects of endurance training on blood pressure, blood pressure-regulating mechanisms, and cardiovascular risk factors. Hypertension 2005; 46; 667-75.

41. Lee LL, Arthur A, Avis M. Evaluating a community-based walking intervention for hypertensive older people in Taiwan: a randomized controlled trial. Prevent Med 2007; 44: 160-6.

42. Moreau KL, Degarmo R, Langley J, et al. Increasing daily walking lowers blood pressure in postmenopausal women. Med Sci Sports Exerc 2001; 33: 1825-30.

43. Murphy MH, Murtagh EM, Boreham CA, Hare LG, Nevill AM. The effect of a worksite based walking programme on cardiovascular risk in previously sedentary civil servants. BMC Public Health 2006; 6: 136.

44. Nemoto K, Genno H, Masuki S, Okazaki K, Nose H. Effects of high-intensity interval walking training on physical fitness and blood pressure in middle-aged and older people. Mayo Clinic Proc 2007; 82: 803-11.

45. Cononie CC, Graves JE, Pollock ML, Phillips MI, Sumners C, Hagberg JM. Effect of exercise training on blood pressure in 70- to 79-yr-old men and women. Med Sci Sports Exerc 1991; 23: 505-11.

46. Palmer LK. Effects of a walking program on attributional style, depression, and self-esteem in women. Percept Mot Skills 1995; 81: 891-8.

47. Braith RW, Pollock ML, Lowenthal DT, Graves JE, Limacher MC. Moderate- and high-intensity exercise lowers blood pressure in normotensive subjects 60 to 79 years of age. Am J Cardiol 1994; 73: 1124-8.

48. Higashi Y, Sasaki S, Sasaki N, et al. Daily aerobic exercise improves reactive hyperemia in patients with essential hypertension. Hypertension 1999; 33: 591-7.

49. Lin JH, Fang CL. Effects of 12 weeks different walking training in borderline hypertensive adolescents. Bulletin of Physical Education 2000; 29; 115-25.

50. Lee LL, Watson MC, Mulvaney CA, Tsai CC, Lo S. The effect of walking intervention on blood pressure control: a systematic review. Int J Nurs Stud 2010; 47: 1545-6.

51. Whelton PK, Appel LJ, Espeland MA, et al. Sodium reduction and weight loss in the treatment of hypertension in older persons: a randomized controlled trial of nonpharmacologic interventions in the elderly (TONE). TONE Collaborative Research Group. JAMA 1998; 279: 839-46. 